\title{
Composição centesimal e perfil dos ácidos graxos de sementes de porongo
}

\author{
Proximate composition and fatty acid profile of seeds of bottle gourd
}

\section{Daniela Batista dos Santos ${ }^{\mathrm{I}}$ Claudia Petry ${ }^{\mathrm{II}}$ Edson Campanhola Bortoluzzi ${ }^{\mathrm{II}}$}

RESUMO

O fruto do porongueiro se destina à fabricação de cuias, utensílios e artesanatos. Em regiões produtoras comerciais de porongo, grande quantidade de frutos $e$, por conseguinte, de sementes são descartadas durante o processo de produção agrícola e industrialização. Nesse sentido, este estudo teve por objetivo avaliar a composição centesimal e o perfil dos ácidos graxos presentes nas sementes de porongo com vistas ao seu uso como matéria prima e alimento. Amostras de sementes de plantas de porongo, semeadas em diferentes épocas de semeadura, foram coletadas em um experimento no município de Rondinha - RS, no ano de 2008. Após secagem das sementes, fez-se a separação $e$ determinação da proporção entre cascas e amêndoas. As amêndoas foram submetidas à avaliação do teor de lipídios, cinzas, proteína bruta, fibra bruta e carboidratos. A composição dos ácidos graxos presentes nos lipídios foi determinada por cromatografia gasosa. As sementes apresentaram elevado teor de carboidratos (33,0\%), lipídios $(37,6 \%)$ e proteína $(25,2 \%)$, sendo que os teores desses componentes não foram afetados pelas épocas de semeadura das plantas. Entretanto, nas plantas semeadas na época mais tardia do ano (terceira época-21/10), elas apresentaram ciclo mais curto (tempo entre semeadura e senescência das plantas, de 149 dias) e frutos cujas amêndoas das sementes apresentaram maior proporção relativa de ácidos graxos insaturados (79,5\%). Os ácidos graxos predominantes em ordem decrescente foram ácido linoleico (C18:2, ômega-6), ácido palmítico (C16:0), ácido oleico (C18:1, ômega 9) e ácido esteárico (C18:0). Os resultados da composição centesimal e do perfil dos ácidos graxos sugerem que as sementes de porongo apresentam um potencial alimentício que necessita ser melhor estudado, com vistas à sua exploração.

Palavras-chave: Lagenaria siceraria (Mol.) Standl, subproduto agrícola, semente de porongo, lipídios, ômega-6.

\section{ABSTRACT}

The fruit of bottlegourd are used for the manufacture of gourd, utensils and handicrafts. Seeds and fruits of bottlegourd are discarded during the manufacturing in producing regions. Thus, this study aimed to evaluate the composition and profile of fatty acids in the seeds of bottle gourd with a view to using the seeds as raw material and food. Seeds of bottle gourd, whose plants were seeded in different growing seasons, were collected in an experiment in the city of Rondinha - RS, in 2008. After drying, it was separated and the ratio of peel and seed kernels. The almonds were subjected to assessment of lipid content, ash, crude protein, crude fiber and carbohydrates. The fatty acid composition of lipids present in the almonds was determined by gas chromatography. The seeds had high carbohydrate content (33.0\%), lipids (37.6\%) and protein (25.2\%), but were not affected by seeding date. However, plants seeded later (on October $27^{\text {th }}$ ) had shorter cycle (time between seeding and senescence of plants, 149 days) and almond had a higher relative proportion of fatty unsaturated acids (79.5\%). The predominant fatty acids in decreasing order were linoleic acid (C18: 2, omega-6), palmitic acid (C16: 0), oleic (C18: 1, omega-9) and stearic acid (C18: 0). The results of centesimal composition and profile of fatty acids suggest a nutritional potential that needs to be better studied with a view to exploiting the bottle gourd seeds.

Key words: Lagenaria siceraria (Mol.) Standl, agricultural byproduct, bottle gourd seed, lipids, omega-6.

\section{INTRODUÇÃO}

O porongo (Lagenaria siceraria (Mol.) Standl.) é uma planta herbácea da família das Cucurbitaceae, tem origem africana (BISOGNIN et

\footnotetext{
IPrograma de Pós-graduação em Ciência do Solo,Universidade Federal de Santa Maria (UFSM), 97105-900, Santa Maria, RS, Brasil. E-mail: agro_daniela@yahoo.com.br. Autor para correspondência.

IPrograma de Pós-graduação em Agronomia, Faculdade de Agronomia e Medicina Veterinária (FAMV), Universidade de Passo Fundo (UPF), Passo Fundo, RS, Brasil. 
al., 2002) e é tradicional em muitos países tropicais e subtropicais (PRAJAPATI et al., 2010), nos quais apresenta uma ampla gama de utilização. Em nível mundial, são conhecidas diversas propriedades medicinais da espécie, como função cardioprotetora (DESHPANDE et al., 2008; FARD et al., 2008); potencial antioxidante (DEORE et al., 2009); atividade diurética, analgésica e anti-inflamatória (SAHA et al., 2011). Já no estado do Rio Grande do Sul, o principal uso do porongo é na fabricação de cuias (BISOGNIN et al., 1997; BISOGNIN et al., 2008), no qual a desuniformidade dos frutos pode chegar a $60 \%$, ocasionando o seu descarte, bem como de suas sementes (BISOGNIN et al., 1999).

Novos usos para a espécie, como os relatados em KATARE et al. (2011), são necessários a fim de minimizar os descartes de subprodutos gerados pela sua produção e industrialização, em especial as sementes. Segundo SANTOS et al. (2010), cada fruto tem, em média, $100 \mathrm{~g}$ de sementes. Dessa forma, um cultivo com produção média de 10.000 frutos ha ${ }^{-1}$ resulta em mais de $1000 \mathrm{~kg} \mathrm{ha}^{-1}$ de sementes. A Cucurbitaceae é apontada por BARBOSA et al. (2010) como a quinta entre as 10 famílias da flora brasileira com potencial para a produção de biodiesel a partir de suas sementes. Segundo FOKOU et al. (2004), podem ser utilizadas para nutrição, pois são fontes de proteína, lipídios, minerais e cálcio. OJIAKO \& IGWE (2007) sugerem o uso das sementes de porongo na alimentação humana e animal. A utilização dos descartes de porongo para a alimentação de aves e suínos em pequenas propriedades rurais é relatada em BISOGNIN et al. (1992). Ainda, o óleo de porongo, para ACHU et al. (2006), pode ser usado tanto no cozimento como em frituras.

Em função do exposto, este estudo objetivou avaliar a composição centesimal e o perfil dos ácidos graxos presentes em sementes de porongo, cujos frutos provêm de plantas semeadas em diferentes épocas do ano.

\section{MATERIAL E MÉTODOS}

\section{Matéria prima}

Em Rondinha (RS), num Latossolo Vermelho, sob as coordenadas geográficas $27^{\circ} 52^{\prime} 09^{\prime}$ ' Sul e 52॰55'09' Oeste, a cultura do porongo foi realizada em três épocas de semeadura: 1) primeira época: fim do inverno (15/09/07); 2) segunda época: primavera (06/10/07); e 3) terceira época: final da primavera $(27 / 10 / 07)$. Vale ressaltar que essas épocas são tradicionais para o plantio dessa espécie no Rio Grande do Sul. O experimento foi instalado sob delineamento experimental inteiramente casualizado, com quatro repetições. Cada parcela experimental perfazia uma área de $200 \mathrm{~m}^{2}$, com espaçamentos entre covas de $5 \mathrm{mx} 5 \mathrm{~m}$. O ciclo total das plantas semeadas na primeira, segunda e terceira épocas foi, respectivamente, de 194, 166 e 149 dias. Mais detalhes em SANTOS et al. (2010). No estádio de maturação fisiológica, os frutos de porongo foram colhidos. Desprezaram-se os frutos danificados, com rachaduras ou perfurações causadas por insetos, selecionando-se aleatoriamente 80 frutos por tratamento (20 em cada repetição), os quais, após a colheita, foram armazenados em local fresco e sombreado por 60 dias, quando então se procedeu o corte da base dos frutos. Passados 15 dias, fez-se manualmente a extração das sementes. As sementes foram secas ao ar e encaminhadas ao laboratório da Engenharia de Alimentos da Universidade de Passo Fundo, onde foram analisadas, em quatro repetições. As sementes foram submetidas à quantificação da massa parcialmente seca (MPS), a qual foi determinada pesando-se as sementes úmidas em balança semi-analítica (Marte, Mod, AL $500 \mathrm{C}, \pm 0,001 \mathrm{~g})$ e distribuindo-as em porções iguais em bandejas de fundo telado, que foram colocadas em estufa elétrica com circulação de ar $\left(a 5^{\circ} \mathrm{C}\right.$, por 6 horas). A quantificação do conteúdo de água (quando em MPS) foi obtida pela razão entre massa de água evaporada e a massa da amostra úmida. Com as sementes secas, determinou-se a proporção de casca e amêndoas, para tal, pesou-se (Marte, Mod, AL $500 \mathrm{C} \pm 0,001 \mathrm{~g}) 100 \mathrm{~g}$ de sementes secas e essas foram submetidas à separação das cascas e amêndoas com o auxílio de um cortador manual (faca). Determinou-se a massa das cascas e das amêndoas separadamente e calculou-se a proporção entre elas, considerando a massa total da semente.

Determinação da composição centesimal

As amêndoas das sementes de porongo foram submetidas à quantificação de lipídios, cinzas, proteína bruta, fibra bruta e carboidratos. $\mathrm{O}$ teor de lipídios foi obtido pela extração direta em Soxhlet, usando hexano p.a. como solvente, pelo período de 6 horas de extração, conforme o método no 032/ IV do INSTITUTO ADOLFO LUTZ (2008). As cinzas foram determinadas pelo método $\mathrm{n}^{\mathrm{0}}$ 018/ IV do INSTITUTO ADOLFO LUTZ (2008). A proteína bruta foi determinada pelo método $\mathrm{n}^{\mathrm{O}} 4$ do MINISTÉRIO DA AGRICULTURA, PECUÁRIA E ABASTECIMENTO (1981). A análise de fibra bruta seguiu a metodologia no 044/IV INSTITUTO ADOLFO LUTZ (2008). O teor de carboidratos foi 
obtido pelo cálculo: 100- (lipídios+cinzas+proteína bruta+fibra bruta). Também se determinou o teor de lipídios de sementes inteiras trituradas, por 2 segundos, em moinhos de facas (Tecator, Knifetec 1095, Sample Mill) em granulometrias entre 6 e 12 mesh. A determinação seguiu o método no ${ }^{-032 / I V ~ d o ~}$ INSTITUTO ADOLFO LUTZ (2005).

Perfil de ácidos graxos

Os ésteres metílicos dos ácidos graxos presentes nos lipídios das amêndoas das sementes de porongo foram obtidos por esterificação do óleo com metanol e ácido sulfúrico, metodologia adaptada de METCALFE et al. (1966). Para a análise de ácidos graxos, utilizou-se cromatografia gasosa (AOCS, 2004). Os compostos foram separados em coluna capilar de sílica fundida CP-Sil $88(50 \mathrm{~m}$ de comprimento $\mathrm{x} 0,25 \mathrm{~mm}$ de diâmetro $\mathrm{x} 0,20 \mu \mathrm{m}$ de espessura do filme), com temperatura de $140^{\circ} \mathrm{C}$ (0min) $1^{\circ} \mathrm{C} \mathrm{min}^{-1}$ até $185^{\circ} \mathrm{C}(0 \mathrm{~min})$. As amostras, em seis repetições, foram injetadas num volume de $1 \mu \mathrm{L}$, injeção em split 1:50, usando como fase móvel $\mathrm{H}_{2}$. Os ácidos graxos foram identificados pela comparação dos tempos de retenção de padrões puros de ésteres metílicos de ácidos graxos com os componentes separados das amostras e a quantificação foi feita por normalização de área (\%).

Análise estatística

As variáveis referentes à composição centesimal e ao perfil dos ácidos graxos foram submetidas à análise de variância, em delineamento DIC. Quando significativas por teste F, as médias foram comparadas por Tukey a $5 \%$ de probabilidade de erro.

\section{RESULTADOS E DISCUSSÃO}

Quando parcialmente secas, $100 \mathrm{~g}$ de sementes frescas apresentaram, em média, 46,3g de água (Tabela 1). A percentagem média de casca e de amêndoa nas sementes secas de porongo foi de $56,2 \%$ e $43,8 \%$, respectivamente. As sementes secas e trituradas apresentaram um teor médio de lipídios de $18,37 \%$, similar ao encontrado por CHISHOLM \& HOPKINS (1964). De acordo com os dados médios da composição centesimal das amêndoas das sementes (Tabela 1), percebeu-se elevado teor de carboidratos $(33,05 \%)$, lipídios $(37,64 \%)$ e proteína (25,25\%), concordando com OJIAKO \& IGWE (2007). O teor de cinzas e fibra bruta foi de 3,90\% e $0,14 \%$, respectivamente. De acordo com os dados apresentados na tabela 1 , as épocas de semeadura não exerceram influência sobre as características e a composição centesimal das sementes, evidenciando que tais valores são característicos da espécie.

O perfil dos ácidos graxos presentes no lipídio da amêndoa não variou em função das épocas de semeadura, conforme tabela 2. Em média, a fração lipídica das amêndoas apresentou predomínio dos ácidos graxos linoleico, palmítico, oleico e esteárico, com proporção relativa média de $67 \%, 15,7 \%, 9 \%$ e 5,9\%, respectivamente (Tabela 2). ACHU et al. (2006), ao analisarem a composição dos ácidos graxos de semente de porongo oriundos de diferentes regiões de Camarões, identificaram a presença de 69,13\%, $13,03 \%, 9,0 \%$ e 7,8\% de ácidos do tipo linoleico, palmítico, oleico e esteárico, respectivamente.

Observou-se que as amêndoas das sementes semeadas na primeira época $(15 / 09 / 07)$ apresentaram maior proporção relativa de ácidos

Tabela 1 - Características das sementes e composição centesimal das amêndoas das sementes de porongo em função de diferentes épocas de semeadura.

\begin{tabular}{|c|c|c|c|c|c|c|c|c|c|}
\hline \multirow{2}{*}{$\begin{array}{l}\text { Época } \\
\text { semeadura* }\end{array}$} & \multicolumn{3}{|c|}{------ Proporção de ------ } & \multirow[b]{2}{*}{ Lipídios $^{* * *}$} & \multicolumn{5}{|c|}{--- Composição centesimal ${ }^{* * * *}$} \\
\hline & $\mathrm{MPS}^{* *}$ & Amêndoa & Casca & & Lipídios & Carboidratos & Proteína & Cinzas & Fibra bruta \\
\hline $1^{\mathrm{a}}$ & $44,5^{\mathrm{ns}}$ & $42,9^{\mathrm{ns}}$ & $57,1^{\mathrm{ns}}$ & $20,66^{\text {ns }}$ & $43,00^{\text {ns }}$ & $25,99^{\text {ns }}$ & $27,01^{\mathrm{ns}}$ & $3,82^{\mathrm{ns}}$ & $0,16^{\mathrm{ns}}$ \\
\hline $2^{\mathrm{a}}$ & 45,1 & 46,5 & 53,5 & 18,54 & 35,86 & 33,99 & 25,95 & 4,04 & 0,13 \\
\hline $3^{\underline{a}}$ & 49,3 & 42,1 & 57,9 & 15,92 & 34,05 & 39,17 & 22,78 & 3,84 & 0,15 \\
\hline Média & 46,3 & 43,8 & 56,2 & 18,37 & 37,64 & 33,05 & 25,25 & 3,90 & 0,14 \\
\hline C.V. $(\%)$ & 6,51 & 6,45 & 5,03 & 14,78 & 27,99 & 34,94 & 5,46 & 5,85 & 36,72 \\
\hline
\end{tabular}

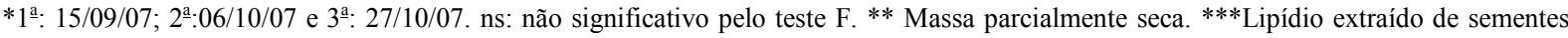
trituradas. $* * * *$ Determinada em base parcialmente seca 
Tabela 2 - Perfil dos ácidos graxos encontrados na fração lipídica das amêndoas de sementes de porongo em função de diferentes épocas de semeadura.

\begin{tabular}{|c|c|c|c|c|}
\hline & $1^{\underline{a}}$ & $2^{\underline{a}}$ & $3^{\mathrm{a}}$ & Média geral \\
\hline 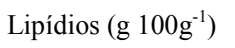 & 43,0 & 35,8 & 34,0 & 37,6 \\
\hline Mirístico (C14:0) & $1,1^{\mathrm{ns}}$ & 0,2 & 0,0 & 0,5 \\
\hline Palmítico (C16:0) & $17,9^{\mathrm{ns}}$ & 15,2 & 14,0 & 15,7 \\
\hline Esteárico (C18:0) & $5,0^{\mathrm{ns}}$ & 6,7 & 6,0 & 5,9 \\
\hline Araquídico (C20:0) & $0,0^{\mathrm{ns}}$ & 0,2 & 0,2 & 0,16 \\
\hline Oleico $(\mathrm{C} 18: 1)$ & $9,0^{\mathrm{ns}}$ & 9,6 & 8,5 & 9,0 \\
\hline Linoleico (C18:2) & $63,4^{\mathrm{ns}}$ & 67,2 & 70,3 & 67,0 \\
\hline Linolênico (C18:3) & $3,5^{\mathrm{ns}}$ & 0,1 & 0,0 & 1,2 \\
\hline$\Sigma$ Saturados & $24,0 \mathrm{~A}$ & $22,3 \mathrm{AB}$ & $20,4 \mathrm{~B}$ & 22,2 \\
\hline$\Sigma$ Insaturados & $75,9 \mathrm{~B}$ & $77,5 \mathrm{AB}$ & $79,5 \mathrm{~A}$ & 77,6 \\
\hline$\Sigma$ Monoinsaturados & $9,0^{\mathrm{ns}}$ & 10,25 & 9,25 & 9,5 \\
\hline$\Sigma$ Poliinsaturados & $66,9^{\mathrm{ns}}$ & 67,3 & 70,3 & 68,1 \\
\hline Sat/Insat ${ }^{* *}$ & $1 / 3,2^{\mathrm{ns}}$ & $1 / 3,6$ & $1 / 4,0$ & $1 / 3,6$ \\
\hline Ole/Lin ${ }^{* * *}$ & $1 / 7,1^{\mathrm{ns}}$ & $1 / 6,6$ & $1 / 7,7$ & $1 / 6,6$ \\
\hline
\end{tabular}

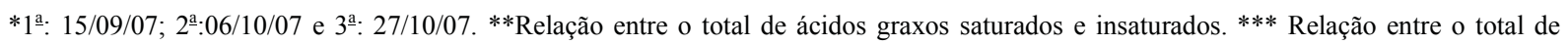
ácidos oleico e linoleico. ns: não significativo pelo teste F. Médias seguidas de mesma letra na linha não diferem pelo teste de Tukey ao nível de $5 \%$ de probabilidade de erro.

graxos saturados e menor proporção relativa de ácidos graxos insaturados, quando comparada com a terceira época de semeadura (Tabela 2). De acordo com LUZIA \& JORGE (2009), a qualidade e digestibilidade de óleos vegetais comestíveis são determinadas pela quantidade e composição em ácidos graxos insaturados. Dessa forma, as amêndoas das sementes de porongo semeados na terceira época $(27 / 10 / 07)$ apresentaram melhor qualidade do óleo vegetal (Tabela 2). Ainda, quanto maior a quantidade de ácido linoleico (C18:2, ômega 6) em relação ao oleico (C18:1, ômega 9), melhor é a qualidade do óleo vegetal em evitar a formação do colesterol ruim (LDL). A relação entre a quantidade de ácido linoleico e ácido oleico foi elevada em todas as épocas de semeadura (Tabela 2). O teor médio de ácido linoleico presente nos lipídios das amêndoas de porongo mostrou-se superior ao teor presente nos óleos de semente de canola, linhaça e oliva apresentados por MARTIN et al. (2006). Ainda, a razão entre os ácidos graxos linoleico (C18:2, ômega 6) e linolênico (C18:3, ômega 3 ) foi de 55,83, semelhante ao observado por MARTIN et al. (2006) no óleo de sementes de milho. Para FOKOU et al. (2009), as características químicas dos óleos de cucurbitáceas são semelhantes ao óleo de milho, algodão e girassol. A proporção relativa de ácidos graxos insaturados, em média, foi de $77,6 \%$, dos quais $9,5 \%$ são de ácidos monoinsaturados e $68,1 \%$ de ácidos poliinsaturados. Dentre os ácidos graxos poliinsaturados, o ácido linoleico destacou-se como sendo o principal componente $(67,0 \%)$ (Tabela 2). Dessa forma, o perfil dos ácidos graxos das sementes de porongo avaliados neste estudo reforça o potencial da espécie no aproveitamento de suas sementes não mais como subproduto da produção artesanal de porongo, mas para fins alimentícios animal e humano.

\section{CONCLUSÃO}

As sementes de porongo apresentam elevado teor de carboidratos $(33,0 \%)$, lipídios $(37,6 \%)$ e proteína $(25,2 \%)$, sendo que a época de semeadura das plantas nas condições subtropicais do estado do Rio Grande do Sul não influencia a composição centesimal das amêndoas das sementes de porongo.

Os ácidos graxos predominantes em ordem decrescente foram ácido linoleico (C18:2, ômega-6), ácido palmítico (C16:0), ácido oleico (C18:1, ômega-9) e ácido esteárico (C18:0). Destacase o predomínio de ácidos graxos insaturados e, destes, os poliinsaturados. As amêndoas de sementes de porongo apresentam maior proporção relativa de ácidos graxos insaturados quando oriundas de plantas semeadas no final da primavera, em comparação às plantas semeadas no inverno.

Os resultados da composição centesimal e do perfil dos ácidos graxos determinados por este 
estudo sugerem que as sementes de porongo, até então um subproduto da agricultura familiar gaúcha, podem apresentar um potencial alimentício, o qual precisa ser melhor estudado.

\section{AGRADECIMENTOS}

À professora Dra. Vera Maria Rodrigues, pelo auxílio nas análises, e ao professor Jorge Gruhn Schulz, pela discussão. Edson Campanhola Bortoluzzi agradece ao Conselho Nacional de Desenvolvimento Científico e Tecnológico (CNPq) pela bolsa produtividade em pesquisa. Claudia Petry agradece ao $\mathrm{CNPq}$ pela bolsa PDE.

\section{REFERÊNCIAS}

ACHU, M.B. et al. Chemical characteristics and fatty acid composition of Cucurbitaceae oils from cameroon. International Union of Food Science and Technology, v.4, p.1249-1259, 2006. Disponível em: <http://iufost.edpsciences.org/index. php?option $=$ com_article $\&$ access $=$ standard $\&$ Itemid $=129 \&$ url $=$ articles/iufost/pdf/2006/01/iufost06000026.pdf>. Acesso em: 15 jan. 2010. doi: 10.1051/IUFoST:20060026.

AMERICAN OIL CHEMISTS SOCIETY (AOCS). Official methods and recommended practices of the American oil chemist's ociety. 5.ed. Champaign, 2004. 1200p.

BARBOSA, M.O. et al. Famílias na flora brasileira com sementes potencialmente indicados para aproveitamento na produção de biodiesel. In: CONGRESSO BRASILEIRO DE MAMONA 4., e SIMPÓSIO INTERNACIONAL DE OLEAGINOSAS ENERGÉTICAS, 2010, João Pessoa, PB. Anais... Campina Grande: Embrapa Algodão, 2010. p.107-111.

BISOGNIN, D.A. et al. Densidade de semeadura e produtividade do porongo. Ciência Rural, v.22, n.1, p.15-19, 1992.

BISOGNIN, D.A. et al. Efeito do tamanho de fruto e do método de extração na qualidade fisiológica de sementes de porongo. Ciência Rural, v.27, n.1, p.13-19, 1997. Disponível em: <http://www.scielo. $\mathrm{br} / \mathrm{scielo}$.php? pid=S0103-84781997000100003\&script $=$ sci arttext $>$. Acesso em: 16 abr. 2009 doi: 10.1590/S010384781997000100003 .

BISOGNIN, D.A. et al. Germinação e propagação in vitro de porongo. Ciência Rural, v.38, n.2, p.332-339, 2008. Disponível em: <http://www.scielo.br/pdf/cr/v38n2/a06v38n2.pdf>. Acesso em: 16 abr. 2009. doi: 10.1590/S0103-84782008000200006.

BISOGNIN, D.A. et al. Influência da época de extração na qualidade fisiológica de sementes de porongo. Ciência Rural, v.29, n.1, p.7-12, 1999. Disponível em: <http://www.scielo.br/pdf/ cr/v29n1/a02v29n1.pdf>. Acesso em: 16 abr. 2009. doi: 10.1590/ S0103-84781999000100002.

BISOGNIN, D.A. Origin and evolution of cultivated cucurbits Ciência Rural, v.32, n.4, p.715-723, 2002. Disponível em: $<$ http://www.scielo.br/pdf/cr/v32n4/a28v32n4.pdf $>$. Acesso em: 16 abr. 2009. doi: 10.1590/S0103-84782002000400028.

BRASIL. Ministério da Agricultura, Pecuária e Abastecimento. Secretaria Nacional de Defesa Agropecuária. Laboratório Nacional de Referência Animal (LANARA).Portaria 001, de 07 de outubro de 1981. Métodos analíticos oficiais para controle de produtos de origem animal e seus ingredientes: métodos físico-químicos. Diário Oficial da União, Brasília, DF. 13 de out. de 1981.

CHISHOLM, M.J.; HOPKINS, C.Y. Fatty acid composition of some cucurbitaceae seed oils. Canadian Journal of Chemistry, v.42, n.3, p.560-564, 1964. Disponível em: <http://www. nrcresearchpress.com/doi/pdf/10.1139/v64-082>. Acesso em: 15 jan. 2010. doi: 10.1139/v64-082.

DEORE, S.L et al. In vitro antioxidant activity and quantitative estimation of phenolic content of Lagenaria siceraria. Rasayan Journal Chemistry, v.2, n.1, p.129-132, 2009. Disponível em: $<$ http://rasayanjournal.com/View-document/166-IN-VITROANTIOXIDANT-ACTIVITY-AND-QUANTITATIVEESTIMATION-OF-PHENOLIC-CONTENT-OF-LAGENARIASICERARIA.html >. Acesso em: 15 jan. 2010

DESHPANDE, J.R. et al. Beneficial effects of Lagenaria siceraria (Mol.) Standley fruit epicarp in animal models. Indian Journal of Experimental Biology, v.46, p.234-242, 2008. Disponível em: $<$ http://nopr.niscair.res.in/bitstream/123456789/4458/1/IJEB $\% 20$ 46(4)\%20234-242.pdf>. Acesso em: 15 jan. 2010

FARD, M.H. et al. Cardioprotective activity of fruit of Lagenaria siceraria (Molina) Standley on doxorubicin induced cardiotoxicity in rats. International Journal Pharmacology, v.4, p.466471, 2008. Disponível em: <http://docsdrive.com/pdfs/ansinet/ ijp/2008/466-471.pdf>. Acesso em: 15 jan. 2010.

FOKOU, E. et al. Chemical properties of some cucurbitaceae oils from cameroon. Pakistan Journal of Nutrition, v.8, n.9, p.13251334, 2009. Disponível em: <http://www.pjbs.org/pjnonline/ fin1462.pdf>. Acesso em: 15 jan. 2011.

FOKOU, E. et al. Preliminary nutritional evaluation of five species of egusi seeds in cameroon. African Journal of Food, Agriculture, Nutrition and Development, v.4, n.1, p.1-11. 2004 Disponível em: <http://www.bioline.org.br/request?nd04005>. Acesso em: 15 jan. 2010.

INSTITUTO ADOLFO LUTZ. Métodos físico-químicos para análise de alimentos. 4.ed. São Paulo:Instituto Adolfo Lutz, 2008. 1020 p.

KATARE, C. et al. Lagenaria siceraria: a potential source of anti-hyperlipidemic and other pharmacological agents. Current Nutrition \& Food Science, v.7, p.286-294, 2011. Disponível em: $<$ http://www.researchgate.net/publication/224877041_Katare Charu Agrawal Supriya Jain Meenu Rani Srishty Saxena Sonali_Bisen_Prakash_S_and_Prasad_GBKS._Lagenaria_ siceraria A Potential Source of Antihyperlipidemic and other_Pharmacological_Agents._Current_Nutrition_F Food Science_7_286-294_\%282011\%29>. Acesso em: 20 mar. 2012.

LUZIA, D.M.M.; JORGE, N. Composição centesimal, potencial antioxidante e perfil dos ácidos graxos de sementes de jambolão (Syzygium cumini L.). Revista Ciência Agronômica, v.40, n.2, p.219-223, 2009. Disponível em: <http://redalyc.uaemex.mx/src/ inicio/ArtPdfRed.jsp?iCve $=195318233008>$. Acesso em: 15 jan. 2010

MARTIN C.A. et al. Ácidos graxos poliinsaturados ômega-3 e ômega-6: importância e ocorrência em alimentos. Revista de Nutrição, v.19, n.6, p.761-770, 2006. Disponível em: <http:// www.scielo.br/pdf/rn/v19n6/10.pdf>. Acesso em: 15 jan. 2010. doi: $10.1590 / \mathrm{S} 1415-52732006000600011$ 
METCALFE, L.D. et al. Rapid preparation of fatty acid esters from lipids for gas chromatographic analysis. Analytical Chemistry, v.38, p.514-515, 1966. Disponível em: <http://pubs. acs.org/doi/pdf/10.1021/ac60235a044>. Acesso em: 15 jan. 2010. doi: 10.1021/ac60235a044.

OJIAKO, O.A.; IGWE, C.U. Nutritional and anti-nutritional compositions of Cleome rutidosperma, Lagenaria siceraria, and Cucurbita maxima seeds from Nigeria. Journal of Medicinal Food, v.10, n.4, p.735-738, 2007. Disponível em: $<$ http://online. liebertpub.com/doi/pdf/10.1089/jmf.2007.625>. Acesso em: 15 jan. 2010. doi:10.1089/jmf.2007.625.

PRAJAPATI, R.P. et al. Phytochemical and pharmacological review of Lagenaria siceraria. Journal of Ayurveda and
Integrative Medicine, v.1, n.4, p.266-272, 2010. Disponível em: $<$ http://www.ncbi.nlm.nih.gov/pubmed/21731373>. Acesso em: 15 jan. 2011. doi: 21731373.

SAHA, P. et al. Antihyperglycemic activity of Lagenaria siceraria aerial parts on streptozotocin induced diabetes in rats. Diabetologia Croatica, v.40, n.2, p.49-60, 2011. Disponível em: <http://www. idb.hr/diabetologia/11no2-3.pdf>. Acesso em: 18 jun. 2012.

SANTOS, D.B. et al. Cobertura de solo e produção de porongo sob diferentes configurações de cultivo. Ciência Rural, v.40, n.3, p.527-533, 2010. Disponível em: <http://redalyc.uaemex.mx/ redalyc/pdf/331/33118930037.pdf>. Acesso em: 15 abr. 2010. doi: 10.1590/S0103-84782010005000034 